\title{
Wildfire hazard and Risk modelling in the Northern regions of Ghana using GIS-based Multi-Criteria Decision Making Analysis
}

\author{
Moses Asori \\ Department of Geography and Rural Development, Kwame Nkrumah University of Science and Technology \\ Kumasi, Ghana \\ Dogbey Emmanuel* \\ Department of Geography, University of Durham, Durham, United Kingdom \\ Gift Dumedah $(\mathrm{PhD})$ \\ Department of Geography and Rural Development, Kwame Nkrumah University of Science and Technology, \\ Kumasi, Ghana
}

\begin{abstract}
There has been tremendous adverse impact of fire outbreaks across the world over the last two decades. The human cost has been devastating and economic losses have exceeded an annual average of US $\$ 2500$ million. Regardless of its importance in plant community regeneration, wildfires have been tremendously devastative to human societies and Earth's ecosystems. To adequately manage wildfires and reduce their adverse effects, estimating the probability of occurrence of wildfires and critically assessing the spatially variable environmental conditions that affect the propagation and impact of these fires is imperative. This study integrates the broader biophysical and environmental variables with anthropogenic factors to model and predict spatial variation in hazard, vulnerability and risk of wildfires in the Savannah, Northeast and Northern regions of Ghana. These areas are characterised by endemic poverty and agrarian activity, which is the major source of livelihood for about $71 \%$ of the population. Disasters such as wildfires are therefore detrimental, severely undermining the natural capital relied on for livelihoods and further aggravating the high poverty rates in these regions. Against this backdrop, a GIS-based Multi Criteria Decision Making Analysis method (GIS-MCDA) - the Analytical Hierarchy Process (AHP) was used to map wildfire hazard and risk within these regions to aid response and mitigation. A wildfire risk map was then produced by developing and integrating hazard and vulnerability models. Results indicate that about $71.7 \%$ $\left(48035 \mathrm{~km}^{2}\right)$ of the study area is highly exposed to wildfire hazard and about $13 \%$ of the study region is likely to experience the greatest risk when wildfires occur, although this is concentrated around urban settlements. It is recommended that future studies integrate intersectional social and economic characteristics to provide a more robust definition of vulnerable and at-risk communities and cultural infrastructure.
\end{abstract}

Keywords: Wildfires, Vulnerability, Risk, GIS multi-criteria decision making, Northern Ghana

DOI: $10.7176 / \mathrm{JEES} / 10-11-02$

Publication date: November $30^{\text {th }} 2020$

\section{Introduction}

Forest and wildfires are considered a crucial aspect of land management in many regions and are considered relevant to the regeneration of other plant species, and agricultural activity in many communities. Globally, about six million square kilometres of land has been transformed by fires in less than 200 years (Kanga et al., 2014). While a large part of global wildfires has minimal consequences for human lives or property, the fire events that do affect human society often have severe adverse effects (Doerr \& Santín, 2016). About 17,000 deaths were attributed to fire outbreaks in Europe in 2009 alone, property damage from fire events in the USA in 2016 exceeded $\$ 70$ billion and since the turn of the 21 st century, more than 80,000 persons have been affected by wildfires in Africa (Thomas et al., 2017; Taffesse, 2020).

In Ghana, the EM-DAT (Emergency Events Database) records only one incidence of wildfires as far back as 1985, with more than 1500 persons affected and four dead (EM-DAT, 2020). This might give an impression that forest fires are not a frequent or severe hazard in Ghana. In reality, the event inclusion criteria does not favour minor, localized events whose impacts are often devastating for the affected local communities. Specifically, the inclusion criteria for EM-DAT requires that at least one of three requirements need to be met: at least 10 deaths need to be recorded, more than 100 persons need to be affected or the affected country must declare a state of emergency or appeal for international assistance. In Ghana, more than \$20 million of annual GDP had been lost to wildfires by 2006 (Appiah et al., 2010) and between 2007 and 2013, about 3,000 wildfire events were recorded by the Ghana National Fire Service. Northern Ghana which comprises the Savannah, Northeast and Northern regions (herein referred to as Greater North) consistently experiences wildfires, which have shown an increasing trend between 2000 and 2013 (Addai et al., 2016).

The Greater North is disproportionately affected by forest fires, with more than $50 \%$ of annual vegetation 
burns across the country recorded in the region (Kugbe et al., 2012). Much of the annual fires in Northern Ghana occur in the Savannah region during prolonged dry periods and are usually induced by anthropogenic activities (Kugbe et al., 2012; Nyadzi et al., 2015). There is strong reliance on the Savannah for livelihood and sustenance and small, controlled fires are relied on as a tool for hunting, clearing land for crop cultivation and improving soil fertility (Amoako \& Gambiza, 2019). Despite the usefulness of these fires for livelihoods across the Greater North of Ghana, there is a tendency for small-scale fires to get out of control and expand into large fires that pose severe threats to the societies within this region (Doe, 2008). The Savannah is extremely fragile and these fires negatively impact soil structure and biodiversity, further exacerbating the prevailing problems of desertification and biodiversity extinction in addition to the direct adverse consequences for individuals living across the Greater North of Ghana (Eriksen, 2007).

The wide-ranging adverse consequences of forest fires in Greater North, coupled with the expectation that climate change will lead to an increase in the duration of dry spells has induced proactive action from the Environment Protection Agency and local authorities. Much of the institutional risk reduction efforts have been targeted at enhancing capacities of local people in using controlled fires for agricultural activity and in responding to fire outbreaks (Appiah et al., 2010; Otutei, 2014). While this is a useful strategy for reducing the impact of wildfires when they occur, an efficient knowledge base does not exist on the potential coverage and impact of future fires to guide mitigation policy and implementation of risk reduction measures. In this regard, modelling forest fires becomes a useful strategy to define levels of risk and for resource allocation to implement targeted interventions that yield maximum benefits. Much of the academic literature in Ghana seems to be in tandem with existing governmental institution approaches to forest and wildfire management, focusing on evaluating perceptions of local communities, changing attitudes and enhancing capacities. Thus, few studies prioritize the simulation of forest fire behaviour or likely impact. Addai et al., (2016) analysed the temporal trend of fire outbreaks in Ghana (2000 - 2013), emphasizing personal responsibility in the increased occurrences and severity of fire events across the country. Gyasi, (2016) investigated the economic cost of fires in industrial nodes and Kugbe et al., (2012) provided an assessment of temporal variations in annual wildfire occurrences in Ghana. Yakubu and Duker, (2015) provided a review of methods for modelling forest fire risk, and Kumi-Boateng and Yakubu, (2016) developed a methodology to model the likely spatial coverage of forest fires and applied it to a forested area within southern Ghana. This paper therefore seeks to contribute towards addressing the relative absence of wildfire risk and hazard simulations in the Ghanaian literature and aims to provide an evidence base to support institutional risk reduction plans.

Concerns about accuracy and subjectivity exist for wildfire modelling techniques such as the Weighted Sum Model and Logistic regression model (Yakubu \& Duker, 2015). In their study on reviewing methods for modelling fire outbreaks, Yakubu and Duker (2015) recommended that the spatial multi-criteria decision-making systems must be considered if we should hope to achieve a leveraged management and mitigation efforts. Savannah, Northeast and Northern region, Ghana - as part of poverty-stricken regions in the country have been suffering from devastative impact of bush fires resulting in the destruction of farmlands and other life sustaining properties. Therefore, urgent action is required to address this menace in the region where poverty levels are already high. Accordingly, this study seeks to model wildfire hazard and risk within the Northeast, Savannah and Northern regions of Ghana, where the savannah, grassland vegetation covers and farmlands have been experiencing annual wildfires. The work effectively incorporates several factors such as land use, anthropogenic, climatic and topographic factors that facilitate the ignition and subsequent spread of wildfires. This task is achieved by using the spatial multi-criteria decision making approach through Geographic Information Systems (GIS) and remote sensing application in order to better understand and predict the behaviour of wildfire hazards and risk within the three Northern regions of Ghana for appropriate mitigation effort.

\section{Study area and methods}

\subsection{Study area}

The study area shown in Figure 1 covers the three Greater North regions namely Northeast, Northern and Savannah regions. These were a single region until 2019, when new legislation created the three new regions referred to above. However, they have been treated as one big region in this study and referred to as Greater North because the available data has not been updated to reflect the present administrative divisions to aid a comprehensive spatial analysis. The Greater North region is bordered on the north by the Upper East and Upper West regions of Ghana, on the east by the eastern Ghana-Togo international border, on the south by the Brong Ahafo region region, and on the west by Ivory Coast. It used to be the biggest region until its division in 2019. It covers an area of approximately $70,384 \mathrm{~km}^{2}$ with a recorded population of 2,479,461 from the 2010 population census.

This region has topographically flat terrain associated with low elevation (less than $250 \mathrm{~m}$ except the far northwest which rises to $500 \mathrm{~m}$ ) and features mainly high plains. The lowest elevation areas are found in the middle of the Voltaian Sedimentary Basin, around Tamale (Carrier et al., 2008). The region is also drained by water bodies such as the Lake Volta, White Volta, Black Volta, Oti River, and the Gbongbo. Most rivers and streams in the 
Greater North are intermittent with a high seasonal flow variation. Climatically, this region is much drier than the southern areas of the country due to its relative proximity to the Sahel and the Sahara. The region is classified as a dry region with a single maxima rainfall period (from July-December), with an average annual rainfall from 750 to $1050 \mathrm{~mm}$. Temperature is generally high in the area, rising up to $40^{\circ} \mathrm{C}$ and rarely falling below $26^{\circ} \mathrm{C}$. The area also has a high diurnal temperature, with temperature mostly high during the day and relatively low during the night. Humidity is also lower in the dry season and high in the wet season. The main vegetation in this region consists predominantly of grassland and drought-resistant trees such as baobab, shear butter, dawadawa, neem and acacias. The major economic activity in this region includes agriculture and hunting, which accounts for $71.2 \%$ of the economically active population.

\subsection{Methods}

The intensity and spread of forest fires is a function of the complex interactions between the physical environment, anthropogenic factors and limitations of response infrastructure (Valdez et al., 2017). Recent technological advancements in remote sensing and GIS applications have made it possible to capture and integrate the spatial distribution of these variables. Following suggested approaches in the literature for factor identification, weightages and rating (see, Chuvieco \& Kasischke, 2007; Ghorbanzadeh et al., 2019; Kanga et al., 2014; Valdez et al., 2017), a remote sensing and GIS method was used for mapping wildfire hazards and risk in the Greater North of Ghana. An integrated analysis which captures the diversity of factors that is likely to affect the generation and spread of wildfires was adopted and managed using GIS and remote sensing. A total of 20 variables were identified and integrated to develop: (1) a hazard model, (2) a vulnerability model, and (3) a risk model. Five submodels that capture the variation in determining wildfires hazard were developed. These are: fuel, ignition, weather, response and risk detection sub models.

$\checkmark \quad$ The fuel risk model evaluates the spatial variability in fuel types and conditions, which is a significant factor in the identification of areas where wildfire occurrences are likely. This model integrated topographical and vegetation variables such as aspect, vegetation biomass, and fuel type.

$\checkmark$ The ignition risk model evaluates the likelihood of a fire being kindled. Anthropogenic factors have been identified as major contributing drivers to the start of wildfires so variables such as the forest's proximity to settlements, roads and croplands were considered.

$\checkmark$ The weather risk model evaluates the climatic conditions that may induce the spread of wildfires. Variables include wind speed, solar radiation, temperature and rainfall.

$\checkmark \quad$ The risk response model considers various frictions with respect to how easy people respond to the fire control and suppression. Factors such as the distance from settlements, fire service station or waterbodies (land cover), the topographic features such as slope and elevation are considered.

$\checkmark \quad$ The risk detection model considered the likelihood that an ignited fire will be detected by people based on visibility which may be obstructed due to topographic and vegetation cover effect.

\subsubsection{Variables Weightages}

All variables have been weighted using the Analytical Hierarchy Process (AHP) method. First, an extensive literature review was conducted to identify and determine the relative contributions of variables that drive the generation and spread of wildfires and a pairwise comparison matrix was developed. Criteria or factors are placed vertically (from $X_{1}$ to $X_{n}$ ) and horizontally (from $Y_{1}$ to $Y_{n}$ ). Values that represent the relative influence on the overall goal are then assigned to a particular cell. After the pairwise comparison matrix, the cell values are then normalised by dividing each cell value by its column total, to generate a new matrix which is then used to derive the Eigen values or the weights. Further, the consistency degree of each weightage was calculated by deriving the Varimax $(\lambda)$ - used in determining the consistency index. Finally, the consistency ratio (CR) which measures the ratio between the Consistency Index (CI) and the Random Index (RI) was determined. From all the sub-model factor weightages and variables, the CR was significantly lower than 0.1 or $10 \%$ meaning that the weights calculated for each factor are reasonably consistent $(\mathrm{Li}, 2010)$.

The Consistency index is computed using the expression: $=\frac{\operatorname{Varimax}(\lambda)-n}{n-1}$; where $\mathrm{n}$ is the number of factors being considered. The Consistency Ratio is given as: $\mathrm{CR}=\frac{C I}{R I}$;

The five sub-models used for the development of the fire hazard map are described in the following sections.

\subsubsection{Fuel risk sub-modelling}

The ignition, intensity and the rate of spread of wildfires is controlled significantly by the nature and the availability of the fuel and other topographical factors needed to stimulate and spread the fire. This sub model has been weighted the highest following the Analytical Hierarchy Process computation (AHP), in line with other wildfire modelling studies (see Chuvieco, 2015; Chuvieco \& Kasischke, 2007; Guettouche et al., 2011; Kanga et al., 2014). Certain considerations were made in the development of this sub model: (1) certain plant species and land cover types ignite and burn more easily than others, (2) fire spread more easily along steep slopes than gentle slopes, (3) places facing the sun may also receive more irradiance thereby causing fuel to dry fast and stimulate fires and (4) 
the moisture content of the fuel may also determine how fast or slow they burn.

Aspect, slope, elevation, topographic wetness index and fuel type are the variables used in developing this sub-model. An ASTER GDEM was acquired from the United States Geological Survey (USGS) data portal and resampled to 30 meters resolution using the bilinear interpolation technique. Fuel type was derived by acquiring MODIS Land use/Land cover data (for 2018) from the Copernicus Land cover Service (CLS) data portal at 500m resolution covering entire West Africa. After this, geometric transformation and correction were performed and resampled into 100m using the bilinear interpolation resampling method in ArcGIS 10.3.

Fuel type. The nature of fuel type determines the rate with which wildfires will spread as well as the perimeter of its influence (Kanga et al., 2014). MODIS global land use/ land cover data was obtained from Copernicus Land cover Service (CLS) for 2018. This cover type was described using the guidelines provided by the MCD 12Q1 User guidelines, and each assigned rating was in line with guidelines provided by the International GeosphereBiosphere Program (IGBP), based on a degree of impact of different fuel types with respect to wildfire ignition, spread and intensity. The type of fuel will determine its combustibility or flammability. Mostly grassland ecosystem may be more susceptible to wildfires than wetlands ecosystem due to differences in the wetness index of the fuels. Risk rating reclassification was performed in ArcMap 10.3. The risk rating is shown in Table.

Slope which refers to the measure of change of elevation is an important topographic factor that influences the rate of fire spread and intensity, as well as providing frictional effects on the response team (Guettouche et al., 2011). It has been established in the literature that steeper slopes favour wildfire spread and intensity more than gentler slopes (see Chuvieco \& Congalton, 1989; Guettouche et al., 2011; Kanga et al., 2014). This variable was computed from the ASTER GDEM in ArcMap 10.3.

Aspect refers to the directional measure of a slope; the direction to which the slope is facing with respect to the angle of the sun. This important topographic element influence wildfires in diverse ways: by controlling the wind condition, moisture content of the air and therefore influencing the spreading rate and intensity of the fires. Southern and western sides receive more irradiance than the northern and eastern aspects and thereby influence fuel moisture and wind condition differently (Ghorbanzadeh et al., 2019). This variable has been computed (in degrees) from GDEM in ArcGIS 10.3 using the Slope Aspect algorithm.

Elevation. The topographic configuration of Greater North in general ranges from flat to moderately high, except for the North West high plains in the upper west region of Ghana and the Gambaga Scarp in the northeastern part. Elevation was weighted the least with respect to the fuel risk sub-model relative to the fuel type, aspect and slope variables.

The Topographic Wetness Index (TWI) was computed from the ASTER-GDEM using the expression TWI $=$ in $(\mathrm{a} / \tan \beta)$, where $\mathrm{a}$ is the upslope contributing area per unit contour length and $\beta$ is the local slope gradient for reflecting the local drainage potential (Cheng-Hu Zhou et al., 2009). The rating for TWI is shown in Table.

\subsubsection{Ignition risk sub-model}

There is no fire outbreak without a cause. In wildfire control and prevention, it is essential to identify the cause of such fires or the ignition source (Yakubu \& Duker, 2015). Even though wildfires can be caused by both man and nature, the greatest concern has been given to human impact on wildfire ignition since natural factors such as lightning does not have significant impact on ignition (Yahaya \& Amoah, 2013). Human activity is recognised in Ghana as the largest contributor to the ignition of forest fires (Ofori-Kumah et al., 2013). Initially, primary forests will have well developed canopy, less undergrowth and wind speed and less supply of dry fuels. However, the construction of roads through such forests will increase logging of trees thereby increasing the wind speed and increasing the available dry fuels (Yakubu \& Duker, 2015). Similarly, agricultural lands nearby can increase the vulnerability to forest fires especially when farmers practice slash and burn form of agriculture and even hunting (Kanga et al., 2014). In this study, Euclidean distance was used to perform proximity analysis between forests and the nearby roads, croplands and human settlements. Road data was obtained from the Ghana Open Data Initiative (GODI). Settlements and other agricultural lands data were obtained from analysis of MODIS land cover data ( $500 \mathrm{~m}$ resolution) for Greater North, acquired from Copernicus land cover service. It was then geometrically corrected and resampled to $100 \mathrm{~m}$ resolution using bilinear interpolation resampling method in ArcGIS 10.3.

Proximity to croplands. Agricultural activity diminishes the forest cover through clearing of vegetation for crop production, but it has also exposed the forest to wildfires through ineffective agricultural practices such as slash and burn. The African continent is undergoing rapid desertification through bush burning and cutting down of trees for agriculture (Yakubu \& Duker, 2015). Therefore, the closer the forest/bush is to cropland, the more vulnerable it becomes with respect to forest fires. This variable has been weighted the highest at 0.70 based on the AHP approach. Proximity analysis was conducted using the Euclidean distance algorithm.

Proximity to settlement centres. Anthropogenic influence on wildfires has received considerable attention among environmental and disaster management experts. In Ghana, most forest fires are directly attributed to human activity. These consist of direct causes such as burning forest for hunting purposes and indirect causes such as road development, logging or resettlement (Yakubu \& Duker, 2015). The closer the forest is to settlement centres, the greater its vulnerability to forest fire outbreaks. The proximity to human settlement areas was examined (calculated 
using the Euclidean distance algorithm in ArcGIS 10.3) and further reclassified based on risk rating shown in Table 2.

Proximity to road networks. Another important factor worthy of consideration when it comes to modelling wildfires risks and hazards is proximity to road networks. Where roads penetrate primary forest to help in logging, humidity decreases, the density of canopy also decreases, wind speeds increase, and there is always a ready supply of drier fuel and thus roads density and proximity to forests is a strong determiner of wildfire hazards (Maingi \& Henry, 2007). Consequently, forest vulnerability to fires is considerably increased (Nicolas and Beebe 1999). The closer a road is to a forest, the higher the likelihood of a forest fire ignition. The risk rating and weight has been presented in Table 2.

\subsubsection{Weather risk sub-model}

The impact of climatic elements is most variable as compared to the other driving factors and have significant impact on wildfires. Their importance lies in the degree of control they exert on the state and density of the fuel, how fast the fire spreads, the direction and extent of the spread. Generally, variables such as rainfall, irradiance, relative humidity, temperature, wind speed and direction and solar radiation are considered in developing a weather risk index map. For this study, temperature, solar radiation, wind speed and rainfall variables were used.

Wind speed. Wind speed is essential in determining the rate of fuel moisture loss and the rate and extent of fire spreading, as it constitutes the major oxidizing agent - oxygen, the key component in the fire triangle. This data set was acquired from WorldClim. After undertaking pre-processing steps such as geometric correction and resampling into $100 \mathrm{~m}$ using bilinear interpolation resampling method, it was mapped and classified into four classes based on a histogram inspection of the data. After thematic mapping it was then reclassified using the risk index rating value shown in Table.

Temperature. The impact of temperature on forest fires is very significant as it determines how fast the fuel dries, reduces or increases the relative humidity, accelerates evapotranspiration and even determines the value of Topographic Wetness Index (TWI). It was given the second highest weightage. An annual mean temperature dataset spanning 30 years was acquired from WorldClim BO11. It was projected to UTM 84 ZONE 30 and resampled into $100 \mathrm{~m}$ resolution using bilinear interpolation resampling method. Based on the risk rating scheme displayed in Table, it was reclassified in ArcMap 10.3.

Rainfall. The influence of rainfall on overall behaviour of wildfires was also considered. Rainfall also determines the density of fuel availability, the fuel type and the fuel moisture content. Where rainfall is higher, the forest/vegetation cover exhibit exuberance with dense forest canopy. In savannah regions where rainfall is low to moderate, the nature of the forest varies in both the wood type and undergrowth density. Also, where rainfall is high, relative humidity is high thereby suppressing the intensity of forest fires, even including probability of ignition. Annual mean precipitation data was acquired from WorldClim BO11. After resampling, it was reclassified using the risk rating in ArcMap 10.3.

Solar radiation. The amount of solar radiation that an area receives also significantly affect forest fires, as it controls the extent to which fuels dry, the amount of relative humidity in the air and even wind speed. Therefore this variable was included in the weather risk modelling. Data was acquired from WorldClim BO11 (annual mean solar radiation). After re-projection and resampling, it was mapped in ArcMap 10.3 based on the risk rating presented in Table.

\subsubsection{Risk detection sub model}

Effective execution of fire control starts with identifying and locating where the burning is occurring on a timely manner. This refers to the ability to view fire from certain viewpoints. Unseen fires are more likely to cause great destruction to properties than fire that can be observed easily by people. Therefore visibility analysis with respect to wildfire suppression is very important. The visibility from communities was weighted 0.667 whereas visibility from roadside was weighted 0.333 . In this study, settlement centres and road networks maps were utilised as input since people are most likely to see the fire either in the community or on a roadside. Advanced view shed algorithm in QGIS 2.18 was used for this analysis.

\subsubsection{Risk response sub-model}

When wildfires are kindled and their spread has been detected, it is essential that the fire is brought under control to mitigate its impact. The time between detection and fire control is referred to as the fire response time. Several factors may influence the time of response. These include; distance to fire service stations, presence of human settlement, waterbodies, distance to roads, and topographic factors such as terrain ruggedness, slope and even other land cover types. These factors directly or indirectly affect the effectiveness of the responses by increasing spatial friction (motion).

Proximity to roads. Fire response personnel rely on connecting roads to respond effectively to forest/wildfire outbreaks, therefore proximity between the burning site and road is very important factor when modelling how vulnerable a forest may be to wildfires. Even though forest proximity to a road may increase the likelihood of fire ignition, its closeness to roads is also essential during fire control since it decreases the friction and travel time for the personnel. The closer the forest is to a nearby road or accessible to fire fighters, the easier will be the fire 
control. Road network data was acquired from Ghana Open Data Initiative (GODI). Euclidean distance buffer was performed and then reclassified using the rating assigned to it.

Elevation and Slope. The nature of the topography in itself provide a form of friction with respect to the ease with which response team can get to the fire and suppress it. For example, a terrain which is relatively flat, low elevation and slope facilitates a faster movement than when the terrain is rugged, with high elevation and slopes. These variables were mapped by obtaining ASTER GDEM from USGS data portal where it was then projected into UTM 84 ZONE 30 and resampled into 100m using the bilinear interpolation resampling method. Four classes were assigned based on the nature of the histogram under natural breaks. After this, the map was reclassified using the individual ratings shown in Table4.

Land cover types. In locations where fire service stations are unavailable, the local people become instrumental in managing forest fire spread. Hence, their presence within the forest catchment should be considered, as their travel time to the fire scene can affect their response. Also, water serves as an important friction element. Data for evaluating settlement availability was derived from the MODIS Global land use map which is provided by the Copernicus Land Cover data service. The water was acquired by deriving the stream networks from the ASTER GDEM, using various combination of hydrological algorithms such as flow direction algorithm (D8) in ArcGIS 10.3. After that reclassification using the variable rating was done.

\subsubsection{Wildfire hazard map}

All five sub models were integrated using the weighted sum overlay algorithm in ArcMap 10.3 to generate fire hazard map showing areas most susceptible to wildland fire outbreaks within the Greater North.

$\boldsymbol{C F F M}=(0.468 *$ Frsm $)+(0.1434 *$ Wrsm $)+(0.076 *$ Rrsm $)+(0.268 *$ Irsm $)+(0.044 *$ Drsm $)$

Where $C F F M=$ Composite Forest Fire Model. Frsm $=$ Fuel risk sub model; $W r s m=$ Weather risk sub model; Rrsm $=$ Response risk sub model; Drsm is the Detection risk sub model and Irsm $=$ Ignition risk sub model.

\subsubsection{Vulnerability modelling}

The presence of man, properties and other relevant facilities near or within the forest catchment determines their vulnerability to wildfire outbreaks. Here, the vulnerability of people and properties to wildfires is of great importance and has thus been evaluated. Parameters that are of most interest are; (1) degree of urbanisation, that is the closeness of forest to any urban centre, as it may determine the amount of economic loss that could be experienced if forest/wildfire fire should occur; (2) the presence of people. This variable has been determined based on the number of people per unit area that reside close to or within a forested area. This data was obtained from Socioeconomic Data and Application Centre (SEDAC) for the year 2020. (3) The forest's proximity to agricultural lands. The northern part of the country is dominated by agrarian economy, hence the impact of forest fires on crops is a very important factor worthy of consideration. This variable has been computed by Euclidean distance and overlay analysis using cropland map extracted from MODIS land cover map as input. And (4) impact on biodiversity which was evaluated based on proximity and intersection of game reserves with forest.

Using modified expression suggested by Guettouche et al. (2011) the vulnerability of people and properties to wild fires was computed.

$\mathrm{VI}=40 * I P+14 * I U+34 * I V+I B * 11$ where $I P$ is human presence expressed as population density, $I U$ is degree of urbanisation and $I V$ is the impact on agriculture and $I B$ is the impact on biodiversity

\subsubsection{Risk modelling}

Finally the risk map was generated by integrating both the hazard and vulnerable models using the definition proposed by Guettouche et al. (2011) with the expression.

$R_{\text {inc }}=A_{\text {inc }} * V^{\text {inc }}$; where $R_{\text {inc }}$ is the risk index, $A_{\text {inc }}$ is the hazard and $V^{\text {inc }}$ is the vulnerability. Risk evaluation gives the scientists, managers and planners the clearer and better comprehension concerning the exact location and likelihood impact of wildfires on the economy, society and the environment (Ghorbanzadeh et al., 2019).

\section{Results and Discussion}

The results following the construction of the wildfire sub models are presented below. The results illustrate: (1) the identification and mapping of areas susceptible to wildfires, (2) the vulnerability of people and properties to wildfires based on levels of exposure, and (3) the overall risk model that integrated both the hazard and vulnerability maps. The fire hazard model has been developed through the integration of five broad sub models including: fuel, detection, and response, weather, and ignition risk sub models. In total, 20 variables - that captured both the natural and social factors have been identified and integrated for a comprehensive evaluation through GIS Multi-Criteria Decision Analysis (GIS-MCDA).

\subsubsection{The fuel risk sub model}

The fuel risk sub model has been developed based on the fuel types and topographic variables such as slope, elevation and aspect. After assigning them relative weights based on their degree of contribution to wildfires behaviours, various data aggregation and integration techniques have been used to derive the resultant map presented below. Figure 2 shows all individual parameters considered in developing the fuel risk sub model.

From Figure 3 (which provides a visualisation of results from fuel risk modelling), much of the high to very 
high fuel risk exists for a large part of the study region with spatial clusterings of very low to moderate risk. This distinct spatial variability seems to be linked to the distribution of fuel type with a strong correlation calculated between fuel type and fuel risk $\left(R^{2}=0.91 ; p=0.0001\right)$. Areas of grassland have high fuel risk whereas the clusterings of very low to moderate fuel risk are in areas where water bodies, cropland and urban areas dominate. While cautiously attributing the level of fuel risk to the distribution of fuel type in the Greater North as correlation does not imply causation, there is a high level of agreement in the literature on how much various distributions of land cover affect fuel load. Grasslands are highly combustible and dry faster than croplands, water bodies, settlement areas and savannahs due to their rapid manner of moisture loss (Chuvieco et al., 2009).

The impact of elevation is also observed in the distribution of fuel risk in the Greater North. The northernmost and western parts of the study region have much higher elevations, east facing aspects and relatively high topographic wetness. These, combined with the fuel type present (savannah and cropland) contribute towards a low to moderate fuel risk.

\subsubsection{Weather Risk Sub model}

Impact of climatic variables on wildfire behaviours such as its propagation and intensity is very significant and thus merit attention in the determination of wildfire hazards spatially. The amount of energy (solar radiation) varied from ` 15,333 to $17835 \mathrm{KJm}^{-2} \mathrm{day}^{-1}$. Mean temperature is relatively high ranging from 26.7 to approximately 29 degree Celsius. Wind speed was relatively low ranging from 1.36 to $2 \mathrm{~m} / \mathrm{s}$. These variables were weighted with respect to their relative contribution to wildfire behaviours. After mapping them thematically, the weighted sum overlay tool was used to integrate all factors to produce the weather risk sub model that depicted areas with high wildfire hazard with regards to climatic impact.

The weather risk sub-model produced depicts the pattern displayed by the individual variables especially wind speed and solar radiation. As shown in Figure 4, variables like temperature, wind speed and solar radiation increased northward. However, rainfall decreased the further one moves northward - showing a negative correlation with the other climatic variables. Whereas increased intensity and magnitude of the other climatic variables serve to intensify wildfires generation and spread, rainfall serves as suppression factor - where higher rains may reduce dryness and combustibility of the fuel load. It is clear from Figure 5 that high to very high weather risk was recorded in the extreme northeast and west whereas low to very low risk is observed in the south - where except rainfall, all the other climatic variables magnitudes were relatively low. This confirms existing consensus that solar radiation, temperature and wind speed are strong determinants of wildfire outbreaks in several localised and macro environmental settings (Kanga et al., 2014; Trigo et al., 2016)

\subsubsection{Ignition risk sub model}

In wildfire control and prevention, it is essential to identify the cause of such fires or the ignition source (Yakubu \& Duker, 2015). Here, chances of wildfire being kindled has been modelled based on identified anthropogenic influences. Integrating variables like proximities to roads, croplands and communities, the ignition risk sub model has been developed as shown in Figure 6.

From Figure 6 map H4 (Ignition risk map), high to very high ignition risk exists in the central portion of the Greater North, where croplands are closer to forested regions (Figure 6 map E1) and road networks and communities are densely concentrated. Proximity to forested lands is therefore an influential factor in wildfire ignition. The proximity of agricultural land use to forested regions seems to have higher impact on the likelihood of wildfire ignition than the other factors. The western portion of the Greater North has lower ignition risk, which is likely to be function of how far away croplands are from forests and smaller clusters of settlements.

\subsubsection{Detection Risk sub model}

Effective execution of fire control starts with quickly identifying and locating where the burning is occurring. Unobserved fires are more likely to cause great destruction to farmland and properties than fires that can be observed easily by people. Visibility analysis with respect to wildfire suppression is highly essential. The visibility from communities was weighted 0.667 whereas visibility from roadside was weighted 0.333 . In this study, settlement centres and road networks maps were utilised as inputs since people likely to see the fire will either be in the community or on a road side (Yakubu et al., 2013). Advanced viewshed algorithm in QGIS 2.18.15 was used for this analysis. From the map shown (Figure 7), areas especially from the northern tip, some areas in the south-eastern to the western flank has no possible detection possibly due to the nature of the land cover type (mainly savannahs) and the topography (higher elevation and slope). The implication is that, fires ignited in these areas will be difficult to detect. Constant monitoring is therefore required to curtail any wildfires and their impact on both the social and physical environmental elements. However, major portion of the area (Greater North) has possible detection with respect to wildfires detection.

\subsubsection{Risk response sub model}

When forest fires are kindled and their spread has been detected, it is essential that the fire is brought under control to mitigate its impact. The fire risk response sub model was built using variables including, distance to fire service stations, presence of human settlement, waterbodies, distance to roads, and topographic factors such as slope and even other land cover types. 
These factors directly or indirectly affect the effectiveness of response by increasing spatial friction (motion). These factors have been weighted using the AHP, rated and mapped thematically. Their integration to form a single, yet comprehensive model was developed using the weighted sum overlay tool in ArcMap 10.3.

The ease with which a detected fire will be responded to and brought under control with respect to time and movement has been modelled based on spatial movement friction variables. From the final model (Figur8 map Z) the very slow response with respect to friction of movement can be seen in places where we have water bodies, also looking at the extreme northwest, the slow response rate can attributed to the higher slopes and elevation. Generally, the response risk can be correlated to the spatial distribution of topographical features such as slopes and elevation and not cover types per se (except for water bodies).

\subsection{Fire hazard modelling}

All five sub models viz. fuel, detection, response, ignition and weather risk sub models derived through integration of several spatial data layers were weighted and incorporated through GIS based Multi-Criteria Decision Making Analysis (GIS-MCDA). Through the weighted sum overlay facility in ArcMap 10.3, the hazard map was produced for the Greater North area. Figure 9 shows that there is high to very high likelihood that fires will occur on grasslands than other cover types. Grasslands are light fuels and so dry faster and fires occurring over this land cover spread twice as fast as those fires occurring in forested areas. Also, their frequency of occurrence and easiness of propagation has been well documented in several countries including Australia (Cruz et al., 2014). About $47900 \mathrm{Km}^{2}(71 \%)$ of the area is under high to very high hazard condition with respect to wildfires, with maximum severity observed at north-western region which in reality has been experiencing frequent and devastative wildfires. The pattern of the high fires also followed the topographic variables such as elevation. Fires occur in lower elevations than higher ones (Yakubu \& Duker, 2015). Secondly, aspect has influence on the fire hazard behaviour since maximum fires occur in areas where the slope faces the sun more (compare Figure 2 map A and Figure 9) and therefore receives higher amount of irradiance needed to dry fuels and increase the chances of ignition. Very low to low hazards occurred on water bodies and urban areas where there are comparably less combustible fuel loads and greater response rate. Moderate fires however occurred on agricultural lands. Essentially, the pattern of high to low fire hazard is primarily determined by the pattern of fuel load distribution, climatic and topographic variables. However, most of these high fires can easily be controlled since they fall under detectable zones based on the viewshed analysis except for western areas in the Greater North where wildfire hazard is high but with no possible detection. This therefore calls for adequate management system for frequent monitoring and timely response.

It is yet important to note that merely identifying hazardous areas with respect to wildfires is not sufficient to spatially target intervention especially on the affected elements such as humans and other ecological elements. A vulnerability assessment is therefore necessary.

\subsection{Vulnerability Modelling}

The presence of man, properties and other relevant facilities near or within the forest catchment determines their vulnerability to wildfire outbreaks. Here, the vulnerability of people and properties to wildfires fires based on their exposure levels merit great attention and has therefore been quantitatively assessed and displayed to facilitate decision making. From Figure 10 (degree of vulnerability to wildfires model) it is apparent that moderate to very high vulnerability which accounts for $12904.85 \mathrm{Km}^{2}(19.18 \%)$ occurred mostly in urban and agricultural lands. This is definitely not a pleasant observation since most lives and properties (importantly agriculture) are in danger - also displayed in the final risk model in Figure 11..

It is important to note that a generalised vulnerability approach has been adopted in this study. The tendency of individual elements-at-risk or groups to withstand the shocks of wildfires have not been critically considered as different people or biological entities may display differing levels of vulnerabilities - not only on exposure, but ability to recover from the wildfire impact. In this study, vulnerability was primarily defined based on proximity of settlements, agricultural land and other valuable properties (game reserves) to high fire hazard regions. Thus, intersecting factors such as gender, religion, education, and income levels were not considered in defining vulnerability. The adoption of a simplistic vulnerability definition in this study was mainly due to resource constraints and the lack of disaggregated data at a local level.

\subsection{Wildfire Risk model}

Risk evaluation gives the practitioners, managers and planners a clearer and better comprehension concerning the exact location and likelihood impact of wildfires on the economy, society and the environment (Ghorbanzadeh et al., 2019). Using the expression through the definition offered by Guettouche et al. (2011) the fire risk model was developed.

Integrating the degree of hazards and vulnerabilities into a single framework aids in spatial targeting and leveraging mitigation efforts to prevent loss of lives and properties. $30.2 \%\left(20356.67 \mathrm{Km}^{2}\right)$ of the Greater North 
region has very low to low wildfire risk whereas $69.8 \%\left(46971.54 \mathrm{Km}^{2}\right)$ of the study region has moderate to high risk, predominant in areas of crop land and urban settlements.

Although it is only a small part of the Greater North region that has the greatest wildfire risk $\left(8733.22 \mathrm{Km}^{2}\right.$ or $12.98 \%$ ), the concentration of these areas of very high risk in urban settlements and croplands means the impacts of wildfires are likely to be devasting, when the occur. As this is an already precarious region, further adverse impact is likely to erode the gains made in improving livelihoods and may further exacerbate poverty levels in the region.

\section{Conclusion}

This study has critically investigated wildfire outbreaks within the Greater North area, which is made up of Savannah, Northeast and Northern regions of Ghana. Wildfires have caused great destruction to a lot of lives and properties, occasionally leading to food insecurity in these fragile agrarian economies. This research has, through a GIS based Multi-Criteria Decision Analysis (GIS-MCDA), modelled wildfires hazards, vulnerability of exposed communities and valued infrastructure, and risk. From the study, it was revealed that much of the fire hazard $(71.7 \%)$ is present in areas where grassland dominates. Agricultural lands are interspersed across these grasslands, creating suitable conditions for severe adverse impact on livelihoods and food security, when wildfires occur. It was also observed that although wildfire hazard is widely distributed across the Greater North area, the greatest risk (12.98\%) is spatially selective - concentrated in urban centres and some portions of cropland. The developed fuel risk sub model was shown to have a reasonable correlation with the hazard model at $(\mathrm{R}=0.42)$, than the rest of the sub models. Interestingly, response sub model was negatively correlated with the hazard model at $(\mathrm{R}=-$ 0.38). This suggests that as response becomes rapid, wildfires hazard is greatly lessened. Aspect, the directional measure of slope - also contributed significantly to the wildfires situation in the area. Higher elevation areas had low susceptibility to wildfires and this confirms that higher elevations encourage wildfire suppression than ignition and propagation. Climatic variables however were discovered to have moderate impact as per the hazard model developed.

It is important to note that, in modelling the degree of vulnerability to wildfires, intersectional social and economic characteristics of at-risk elements were not analysed. Expected economic cost of wildfires has not also been incorporated into the current study. It is expected that the incorporation of local level vulnerability indicators will increase the greatest risk from what has been currently calculated (12.98\%). Despite this, this study has successfully wildfire hazard, vulnerabilities and risk in the Greater North region. This should be helpful to Ghana's National Disaster Management Organization (NADMO) and Ghana National Fire Service (GNFS) to monitor atrisk areas for timely response and mitigation of wildfire impact.

It is therefore recommended that future studies should incorporate social and infrastructural indicators such as income, level of education, employment status of the local people and significant cultural infrastructure when modelling vulnerability for a more robust identification and assessment of at-risk elements.

\section{References}

Addai, E. K. et al. (2016). Trend of fire outbreaks in Ghana and ways to prevent these incidents. Safety and Health at Work. 7(4), 284-292. doi: 10.1016/j.shaw.2016.02.004, https://doi.org/10.1016/j.shaw.2016.02.004

Amoako, E. E., \& Gambiza, J. (2019). Effects of anthropogenic fires on soil properties and the implications of fire frequency for the Guinea savanna ecological zone, Ghana. Scientific African. 6. doi: 10.1016/j.sciaf.2019.e00201, https://doi.org/10.1016/j.sciaf.2019.e00201

Carrier, M., Lefebvre, R., Racicot, J., \& Asare, E. B. (2008). Northern Ghana hydrogeological assessment project. 33rd WEDC International Conference, Accra, Ghana. 353-361.

Chuvieco, E., \& Congalton, R. G. (1989). Application of remote sensing and geographic information systems to forest fire hazard mapping. Remote sensing of Environment. 29(2). 147-159.

Chuvieco, E., \& Kasischke, E. S. (2007). Remote sensing information for fire management and fire effects assessment. Journal of Geophysical Research: Biogeosciences. 112, 1-8. doi: 10.1029/2006JG000230, https://doi.org/10.1029/2006JG000230

Chuvieco, E., Gonzalez, I., Verdu, F., Aguado, I. \& Yebra, M. (2009). Prediction of fire occurrence from live fuel moisture content measurements in a Mediterranean ecosystem. International Journal of Wildland Fire. 18(4), $430-441$.

Chuvieco, E. (2015). Global characterization of fire activity: Toward defining fire regimes from Earth observation data. Global change biology. 14(7). 1488-1502. doi: 10.1111/j.1365-2486.2008.01585.x, https://doi.org/10.1111/j.1365-2486.2008.01585.x

Cruz, M.G., Sullivan, A.L., Gould, J.S., Hurley, R.J., \& Plucinski, M.P. (2014). Got to burn to learn: the effect of fuel load on grassland fire behaviour and its management implications. International Journal of Wildland Fire, 27(11). 727-741.

Doerr, S. H., \& Santín, C. (2016). Global trends in wildfire and its impacts: Perceptions versus realities in a 
changing world. Philosophical Transactions of the Royal Society B: Biological Sciences, 371(1696). 1-10. doi: 10.1098/rstb.2015.0345, https://doi.org/10.1098/rstb.2015.0345

EM-DAT, (2020). International Disaster Database, Centre for Research on the Epidemiology of Disasters, UCLouvain, Brussels, Belgium. www.emdat.be_(27th August, 2020)

Eriksen, C. (2007). Why do they burn the 'bush'? Fire, rural livelihoods, and conservation in Zambia. Geographical Journal. 173(3), 242-256.

Ghorbanzadeh, O., Blaschke, T., Gholamnia, K., \& Aryal, J. (2019). Forest fire susceptibility and risk mapping using social/infrastructural vulnerability and environmental variables. Fire. 2(3). 1-27.

Guettouche, M. S et al. (2011). A fire risk modelling and spatialization by GIS. Journal of Geograpbic Information System. 3(3). 254-265. doi: 10.4236/jgis.2011.33022, https://doi.org/10.4236/jgis.2011.33022

Gyasi, F. (2016). Exploring the economic effects of industrial fires in Ghana: A case study of manufacturing industries in Tema Metropolis. Master's Thesis, Kwame Nkrumah University of Science and Technology. http://dspace.knust.edu.gh/bitstream/123456789/9098/1/FRANK\%20GYASI.pdf $\quad$ (12th September 2020).

Kanga, S., Sharma, L., Pandey, P.C., \& Nathawat, M. S. (2014). GIS modelling approach for forest fire risk assessment and management. International Journal of Advancement in Remote Sensing, GIS and Geography. 2(1). 30-44

Kugbe, J. X. et al. (2012). Annual vegetation burns across the northern savanna region of Ghana: Period of occurrence, area burns, nutrient losses and emissions. Nutrient Cycling in Agroecosystems, 93(3), $265-284$. doi: $10.1007 /$ s10705-012-9514-0, https://doi.org/10.1007/s10705-012-9514-0

Kumi-boateng, B., \& Yakubu, I. (2016). Modelling forest fire risk in the Goaso forest area of Ghana: Remote sensing and geographic information systems approach. International Journal of Biological and Ecological Engineering. 10(6), 681-688.

Maingi, J. K., \& Henry, M. C. (2007). Factors influencing wildfire occurrence and distribution in eastern Kentucky, USA. International Journal of Wildland Fire, 16(1), 23-33. doi: 10.1071/WF06007, https://doi.org/10.1071/WF06007

Nyadzi, E. et al. (2015). Assessment of trace gas emissions From wildFires in different vegetation types in Northern Ghana: Implications for global warming. Environment and Natural Resources Research, 5(2), 37. doi: 10.5539/enrr.v5n2p3,7 https://doi.org/10.5539/enrr.v5n2p37

Ofori-Kumah, K., Oduro-Appiah, J., \& Ohene, J. B. (2013). Challenges of forest reserve management in Ghana: Evidence from Tain Tributary Block I Forest Reserve. Journal of Environment and Earth Science. 3(11). 138-145.

Otutei, E. (2014). The political ecology of forest management in Ghana: Actors, interests and practices in the Assin North Municipality. Journal of Environment and Earth Science. 4(10). 108-120

Thomas, D. et al. (2017). The costs and losses of wildfires: A literature review. NIST Special Publication 1215. doi: 10.6028/NIST.SP.1215, https://doi.org/10.6028/NIST.SP.1215

Trigo, R. M., Sousa, P. M., Pereira, M. G., Rasilla, D., \& Gouveia, C. M. (2016). Modelling wildfire activity in Iberia with different atmospheric circulation weather types. International Journal of Climatology, 36(7), 2761-2778. doi: 10.1002/joc.3749, https://doi.org/10.1002/joc.3749

Valdez, M. C. et al. (2017). Modelling the spatial variability of wildfire susceptibility in Honduras using remote sensing and geographical information systems. Geomatics, Natural Hazards and Risk. 8(2). 876-892. doi: 10.1080/19475705.2016.1278404, https://doi.org/10.1080/19475705.2016.1278404

Yahaya, A., \& Amoah, S. T. (2013). Bushfires in the Nandom district of the Upper West Region of Ghana: perpetual threat to food crop production. Journal of the Environment and Earth Sciences 3(7). 10-14.

Yakubu, I., \& Duker, A. A. (2015). Review of methods for modelling forest fire risk and hazard. African Journal of Environmental Science and Technology. 9(3), 155-165. doi: 10.5897/AJEST2014.1820, https://doi.org/10.5897/AJEST2014.1820

Yakubu, I., Mireku-Gyimah, D., \& Duker, A. A. (2013). Multi-spatial criteria modelling of fire risk and hazard in the West Gonja Area of Ghana. Research Journal of Environmental and Earth Sciences, 5(5), $267-277$. https://doi.org/10.19026/rjees.5.5660 
Tables and Figures

Table 1: Fuel risk sub model with weights and risk rating.

\begin{tabular}{|c|c|}
\hline Land cover type (weight $=0.468)$ & Risk index \\
\hline Closed Shrub land & 15 \\
\hline Open Shrub land & 14 \\
\hline Woody Savanah & 9 \\
\hline Savannahs & 8 \\
\hline Grasslands & 16 \\
\hline Permanent Wetlands & 1 \\
\hline Croplands & 4 \\
\hline Urban/ Built up area & 3 \\
\hline Mix of cropland/Natural vegetation & 5 \\
\hline Barren lands & 2 \\
\hline Water bodies & 0 \\
\hline Slope (weight $=0.144)$ & Rate \\
\hline $0-5$ & 1 \\
\hline $5-10$ & 2 \\
\hline $10-15$ & 3 \\
\hline $25-35$ & 4 \\
\hline$>35$ & 5 \\
\hline Elevation (weight $=0.044$ ) & Rate \\
\hline $70-200$ & 4 \\
\hline $200-300$ & 3 \\
\hline $300-400$ & 2 \\
\hline $400-800$ & 1 \\
\hline Aspect (weight $=0.268)$ & Rate \\
\hline$-1-45(\mathrm{~N})$ & 1 \\
\hline $46-135(\mathrm{E})$ & 2 \\
\hline $136-225(\mathrm{~W})$ & 4 \\
\hline $226-315(\mathrm{~S})$ & 3 \\
\hline $316-360(\mathrm{~N})$ & 1 \\
\hline Topographic Wetness Index (weight $=0.076)$ & Rate \\
\hline $5-10$ & 1 \\
\hline $10-15$ & 2 \\
\hline $15-20$ & 3 \\
\hline $20-25$ & 4 \\
\hline $25-30$ & 5 \\
\hline$>30$ & 6 \\
\hline
\end{tabular}


Table 2: Ignition risk sub model with parameters weights and rate.

\begin{tabular}{ll}
\hline Agriculture proximity (weight $=0.702)$ & Rate \\
\hline $0-100$ & 7 \\
$100-200$ & 6 \\
$200-300$ & 5 \\
$300-400$ & 4 \\
$400-2000$ & 3 \\
$2000-5000$ & 2 \\
$>5000$ & 1 \\
\hline Road proximity (weight $=0.072)$ & Rate \\
\hline $0-100$ & 7 \\
$100-200$ & 6 \\
$200-300$ & 5 \\
$300-400$ & 4 \\
$400-2000$ & 3 \\
$2000-5000$ & 2 \\
$>5000$ & 1 \\
\hline Settlement proximity $($ weight $=0.2263)$ & Rate \\
$0-100$ & 7 \\
$100-200$ & 6 \\
$200-300$ & 5 \\
$300-400$ & 4 \\
$400-2000$ & 3 \\
$2000-5000$ & 2 \\
$>5000$ & 1 \\
\hline
\end{tabular}

Table 2 shows risk ratings that capture the degree of influence that various classifications of the identified parameters have on ignition risk. A consistency index (CI) of 0.001 and consistency ratio (CR) of 0.0009 was computed. The weight assigned to each parameter, relative to its importance in affecting ignition risk is also shown. Table 3: Weather risk sub model with parameters weights and rates.

\begin{tabular}{ll} 
Wind speed $(\mathrm{m} / \mathrm{s})($ weight $=0.512)$ & Rate \\
\hline $1-1.4$ & 2 \\
$1.4-1.5$ & 3 \\
$1.5-1.7$ & 4 \\
$1.7-1.9$ & 5 \\
$1.9-2.2$ & 7 \\
$>2.2$ & Rating \\
\hline Temperature ranges $($ weight $=0.138)$ & 2 \\
\hline 20 to 22 & 4 \\
22 to 24 & 6 \\
24 to 26 & 8 \\
26 to 28 & 9 \\
28 to 30 & Rating \\
\hline Rainfall $($ mm $)(\text { weight }=0.075)_{200}$ to 400 & 10 \\
400 to 600 & 8 \\
600 to 800 & 6 \\
800 to 100 & 6 \\
$>1000$ & 4 \\
Solar radiation $\left(\mathrm{KJm}^{\wedge}-2\right.$ day $\left.^{\wedge}-1\right)($ weight $=0.275)$ & 2 \\
\hline $10,000-16000$ & Rate \\
$16000-16200$ & 1 \\
$16200-16500$ & 2 \\
$16500-1700$ & 3 \\
$17000-17900$ & 4 \\
$>17900$ & 5 \\
Table prests & 7 \\
\hline
\end{tabular}

Table 3 presents risk ratings for various classifications of the variables that influence weather risk. A consistency index (CI) of 0.009 and consistency ratio (CR) of 0.0101 was computed. The weight assigned to each variable, relative to its importance in affecting weather risk is highlighted. 
Table 4: Risk response sub model with weights and rates.

\begin{tabular}{|c|c|}
\hline Proximity to Road (meters) (weight $=0.076)$ & Risk Rating \\
\hline 0 to 100 & 1 \\
\hline 100 to 300 & 2 \\
\hline 300 to 500 & 3 \\
\hline 500 to 700 & 4 \\
\hline 700 to 900 & 5 \\
\hline 900 to 1100 & 6 \\
\hline 1100 to 5000 & 9 \\
\hline$>5000$ & 10 \\
\hline Slope $($ degrees $)$ (weight $=0.468)$ & Rating \\
\hline O to 5 & 1 \\
\hline 5 to 10 & 2 \\
\hline 10 to 25 & 3 \\
\hline 25 to 35 & 4 \\
\hline 35 and above & 5 \\
\hline Land cover types (weight $=0.143$ ) & Rate \\
\hline Settlement & 1 \\
\hline Agricultural lands & 2 \\
\hline Shrub land & 3 \\
\hline Natural forest & 7 \\
\hline Water & 9 \\
\hline Distance to fire service stations (weight $=0.27$ ) & Risk rate \\
\hline $0-100$ & 1 \\
\hline $100-300$ & 3 \\
\hline $300-500$ & 5 \\
\hline $500-1000$ & 6 \\
\hline $1000-2000$ & 8 \\
\hline $2000-5000$ & 9 \\
\hline$>5000$ & 10 \\
\hline
\end{tabular}

Table 4 shows risk ratings that capture the degree of influence that various classifications of the identified parameters have on risk response. A consistency index (CI) of 0.019 and consistency ratio (CR) of 0.012 was computed. The weight assigned to each parameter, relative to its importance in affecting risk response is also shown.

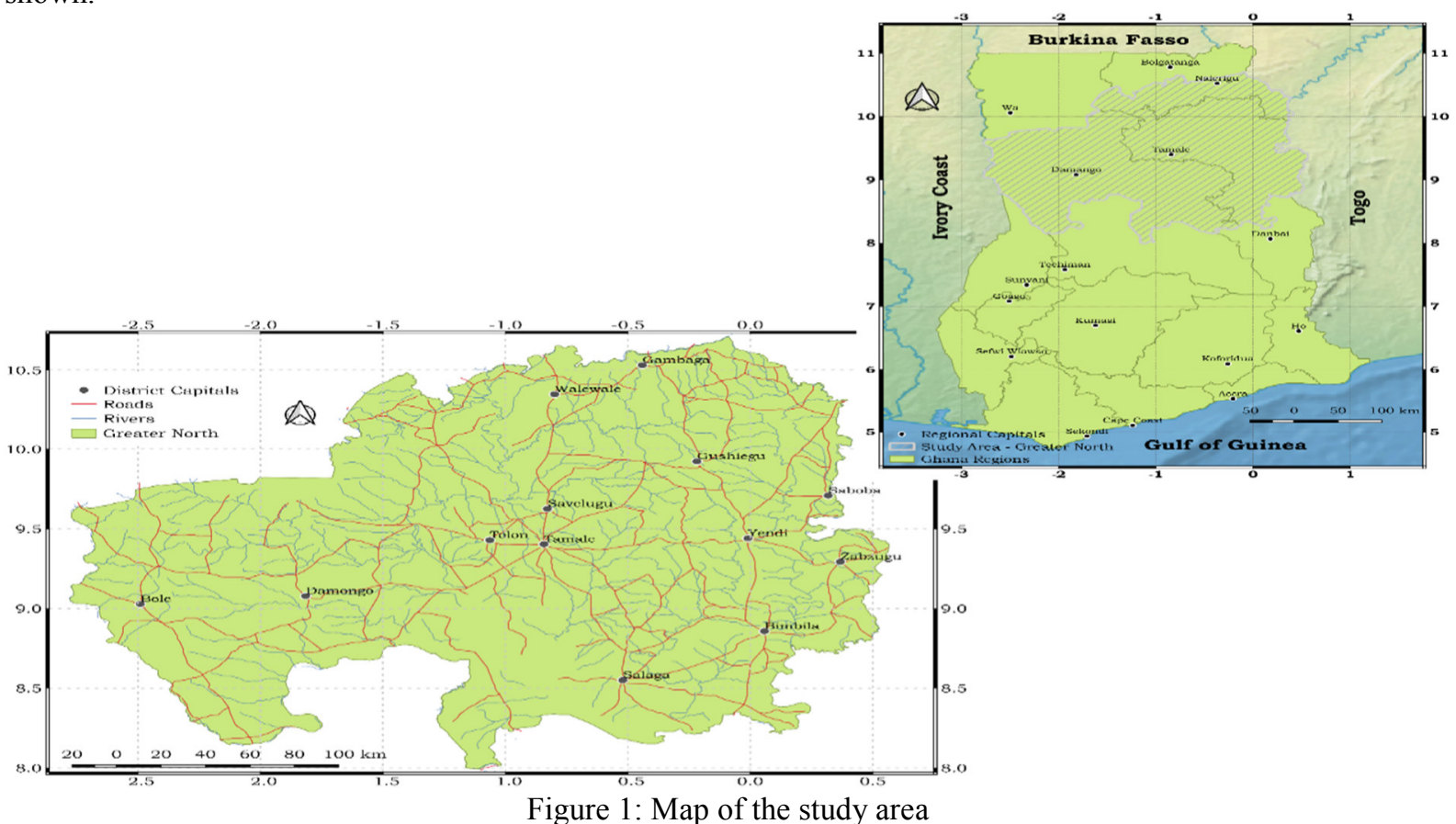

Figure 1 provides a view of the Greater North study region with district capitals and major road networks highlighted(left image) and its spatial context within the country, Ghana (right image) 

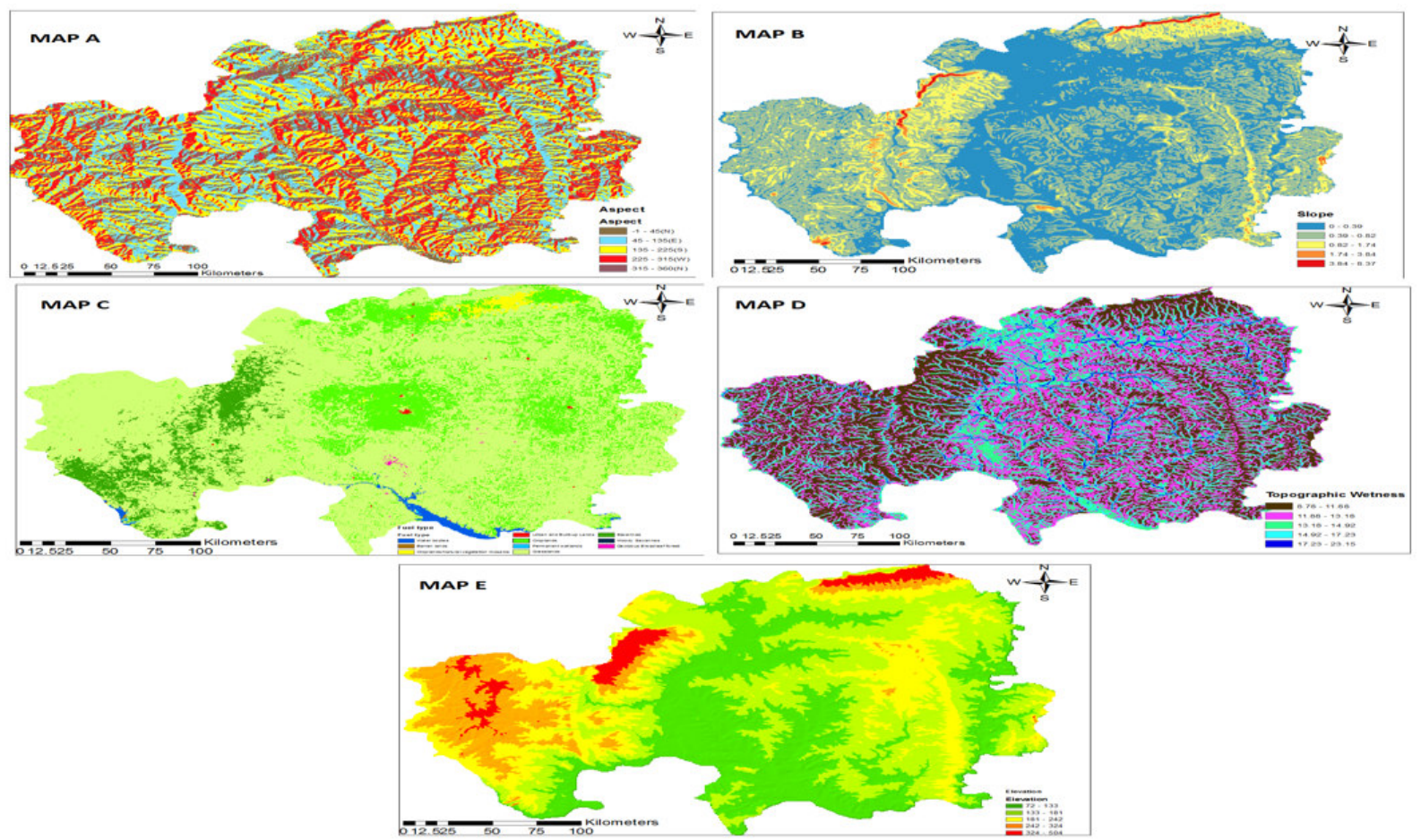

Figure 2: Influential fuel risk parameters

This figure presents individual parameters that contribute to determining fuel risk with regards to wildfire hazards. Map A is the aspect map; map B is the slope; map C is the land cover map used to derive the fuel types and for further rating; map D is the Topographic Wetness Index (TWI) which indicates the terrain wetness in the greater north and map $\mathrm{E}$ is the spatial distribution of elevation in the greater North.

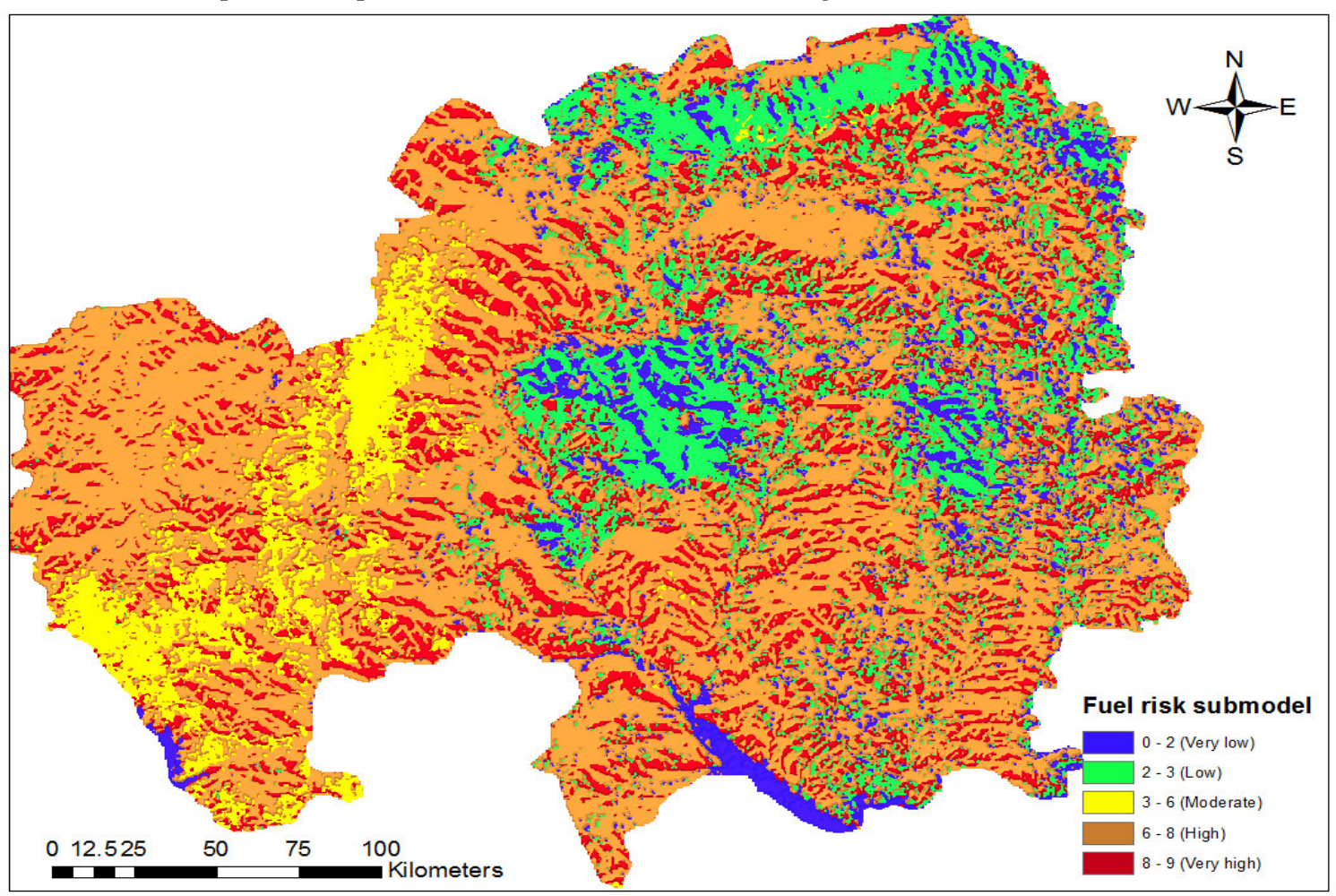

Figure 3: Fuel risk submodel

Figure 3 provides a visualisation of results from fuel risk modelling. Spatial clusters of low to moderate risk are observed, with high to very high distributed across the Greater North region. 

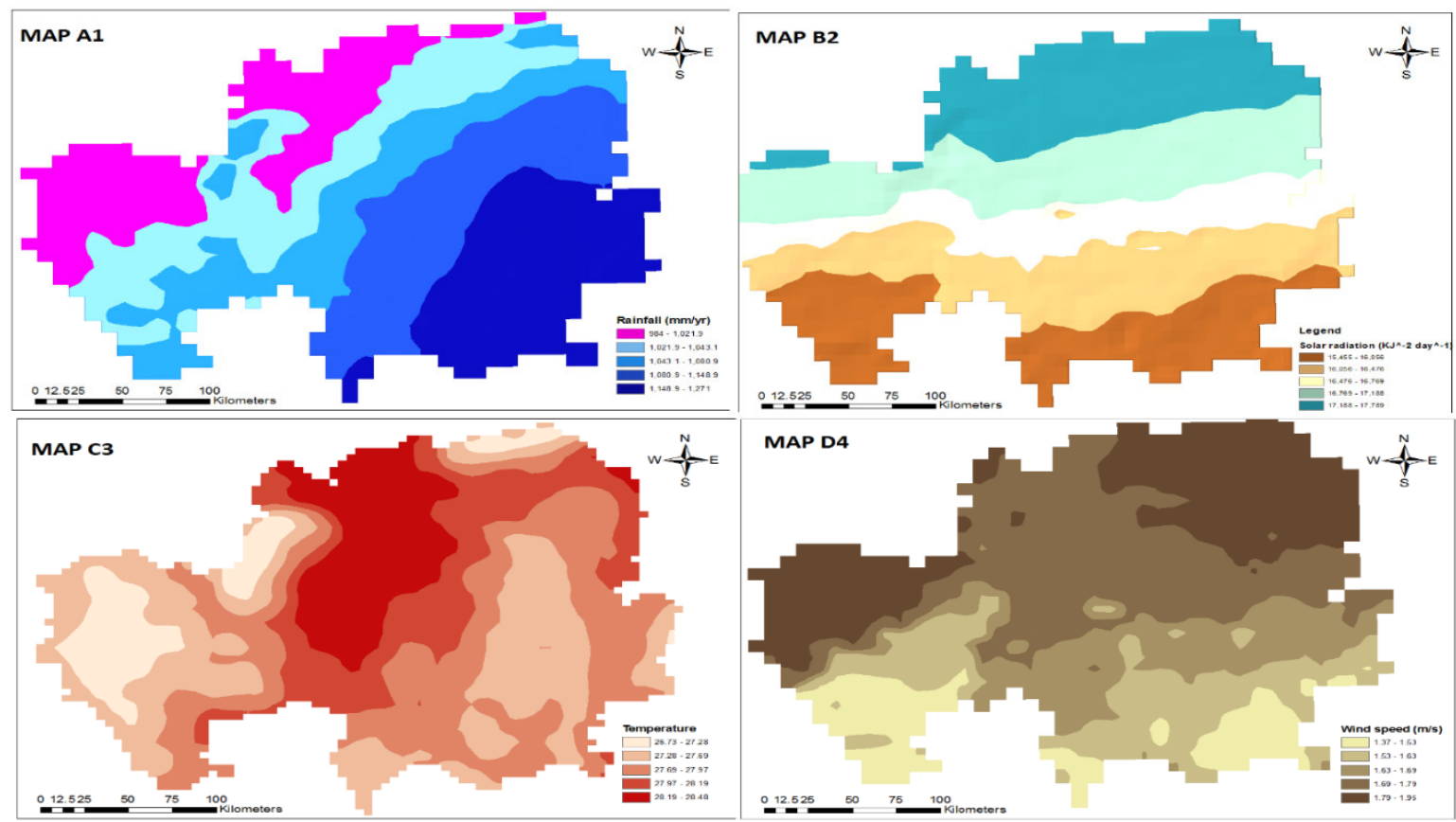

Figure 4: Influential weather risk parameters

This figure shows the combination of factors considered in evaluating weather risk in the Greater North. A1 is rainfall distribution, $\mathrm{B} 2$ is amount of solar radiation received per day, $\mathrm{C} 3$ is average temperature and D4 is wind speed, measured in metres per second.

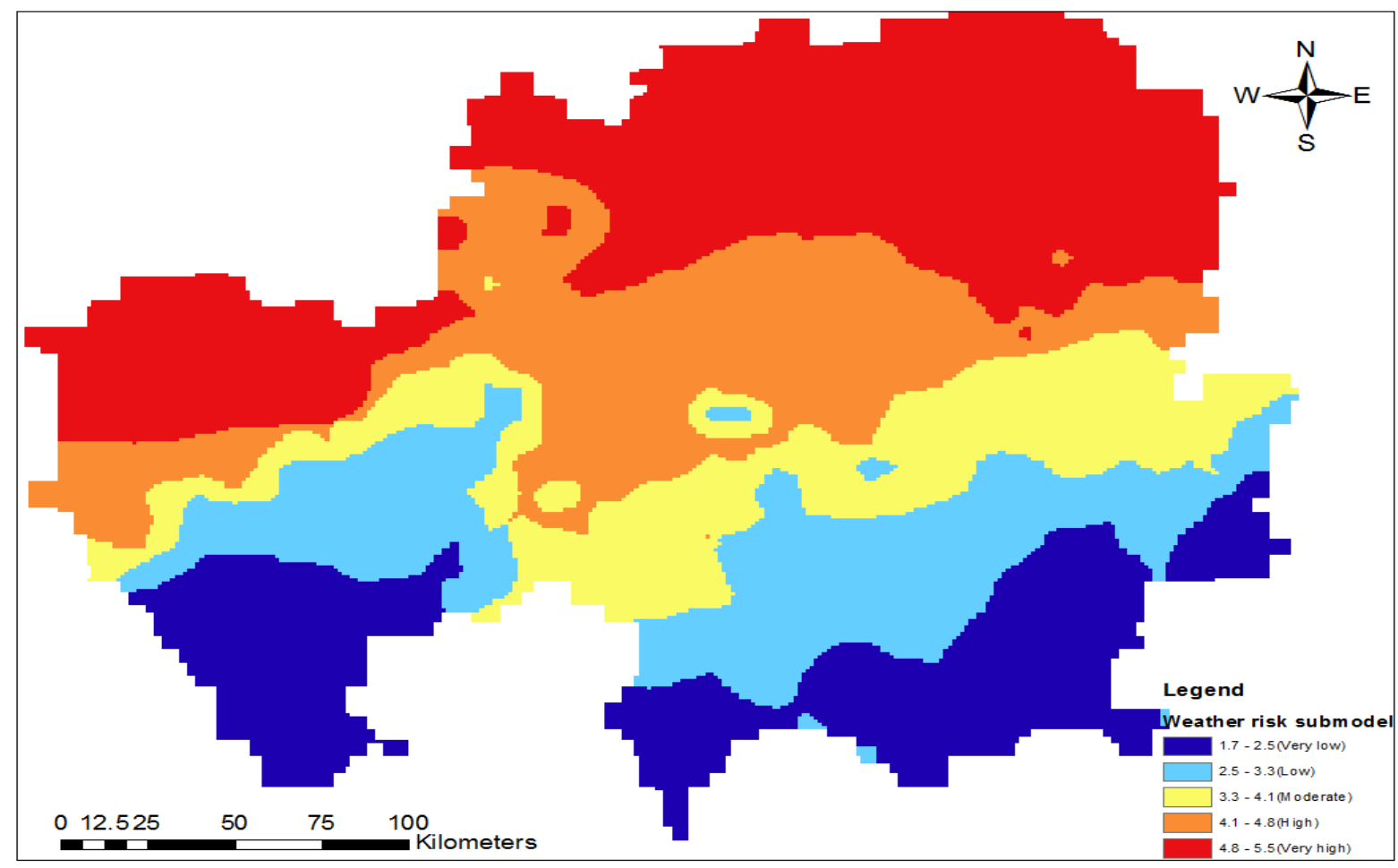

Figure 5: Visualisation of results from weather risk modelling 


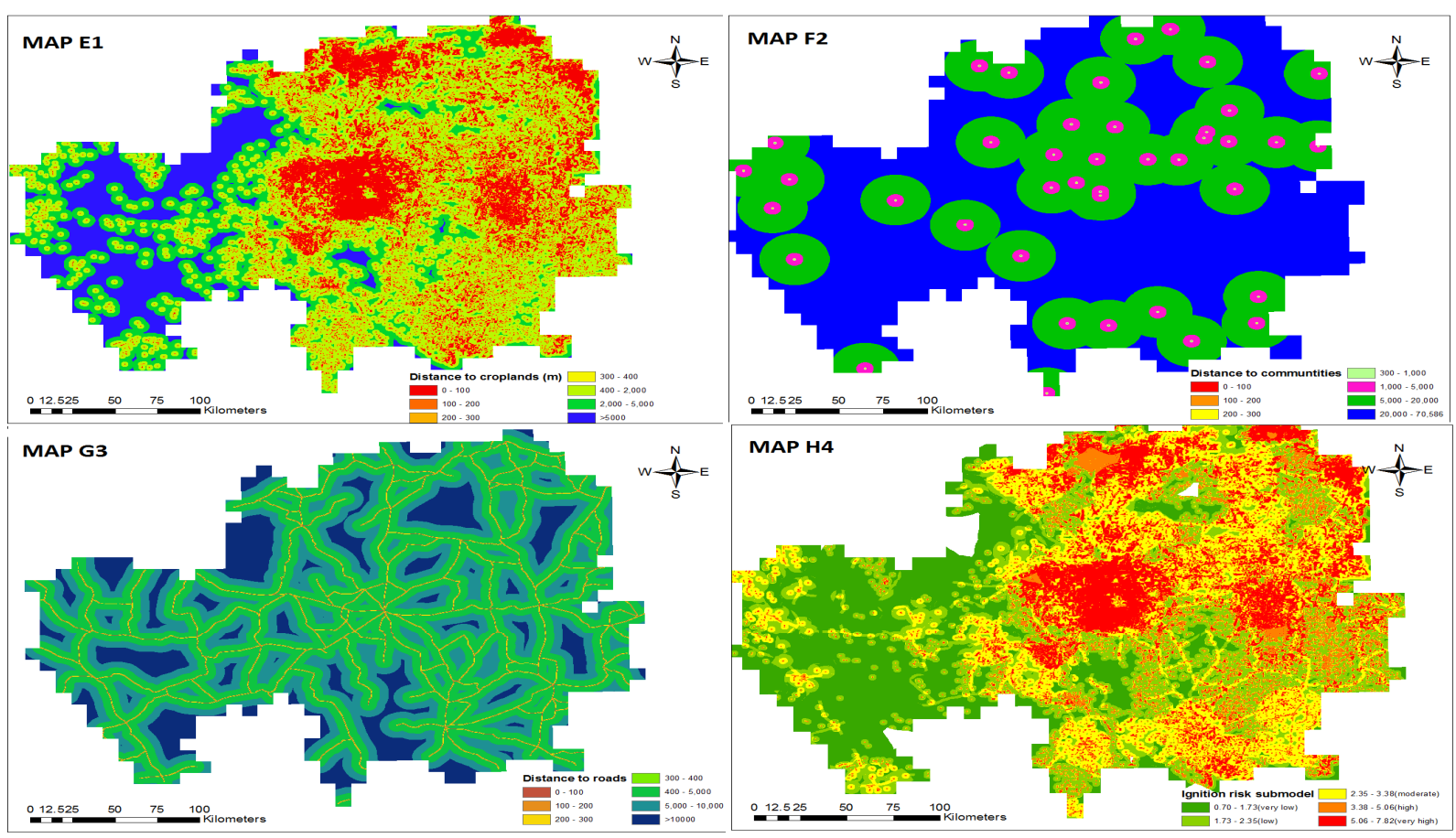

Figure 6: Ignition risk modelling

This figure shows the variables evaluated and integrated to develop an ignition model, whose results are visualised in H4. E1 indicates proximity analysis between cropland and forested areas, F2 is proximity of communities to forested areas, G3 shows distance analysis between road networks and forested lands.

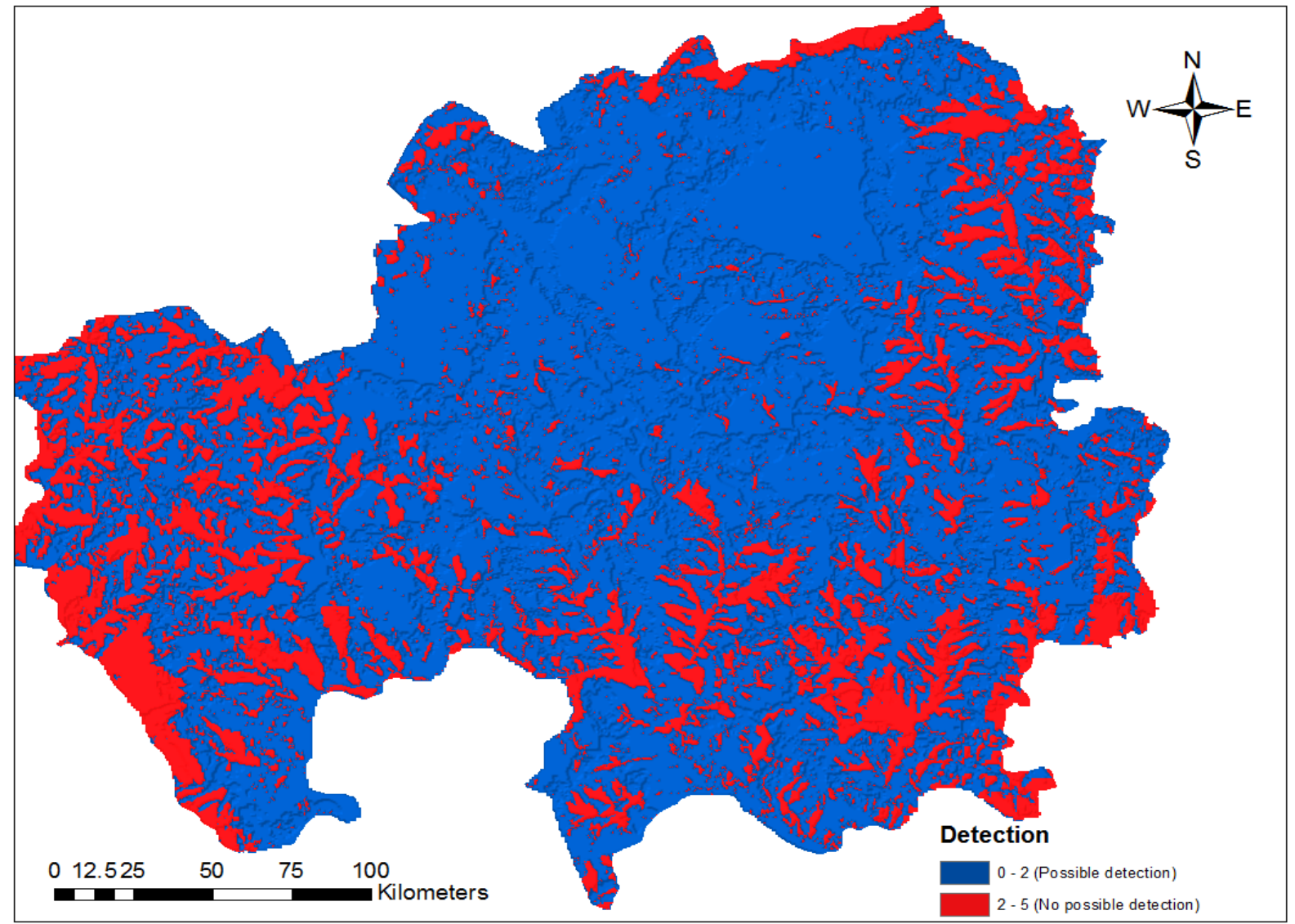

Figure 7: Visualisation of results from risk detection modelling 


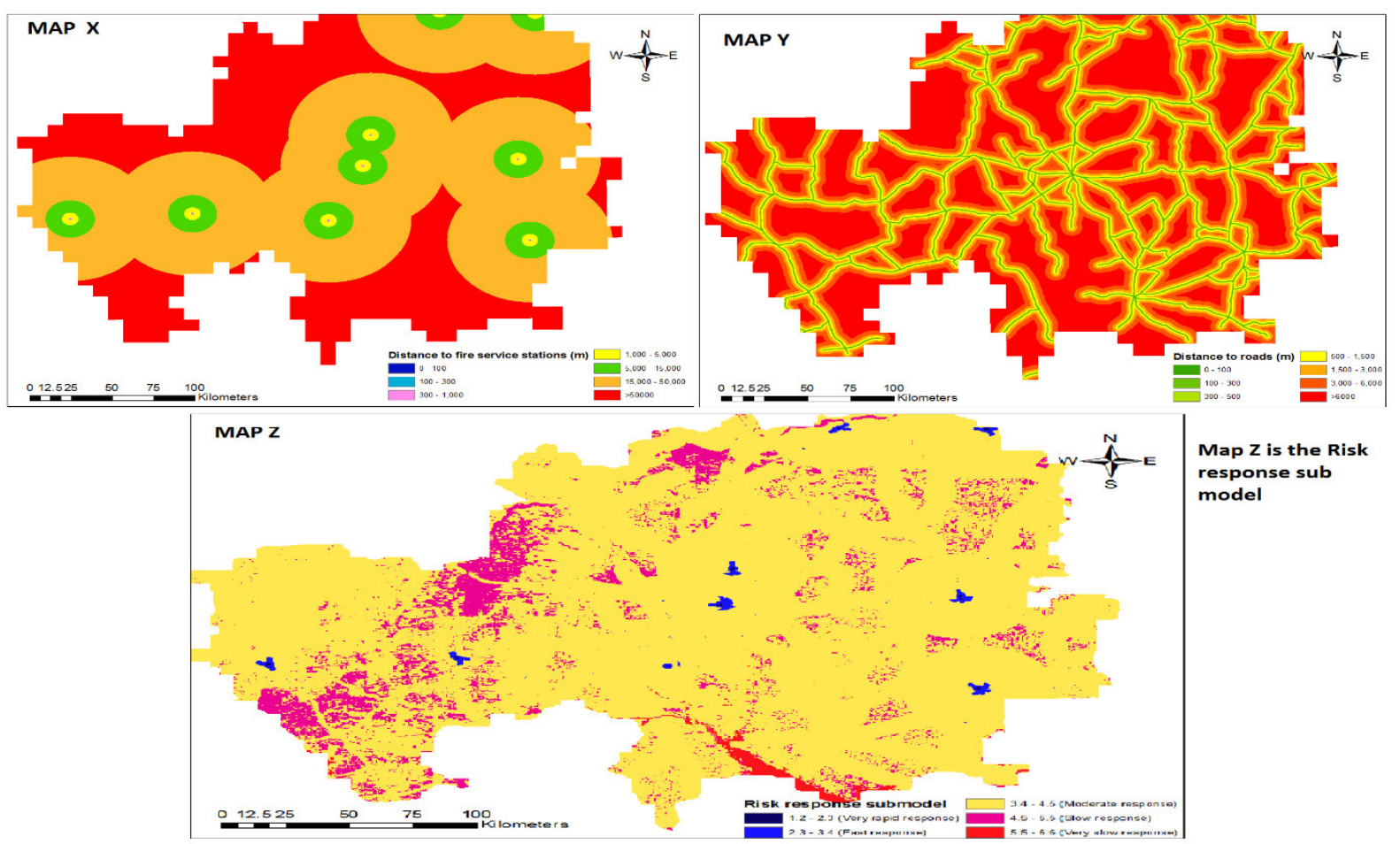

Figure 8: Risk response modelling

This figure shows factors used to derive the risk response model (map Z). X shows proximity of fire service stations to forested land, $\mathrm{Y}$ is proximity of roads to forested areas - which determines distance friction effect

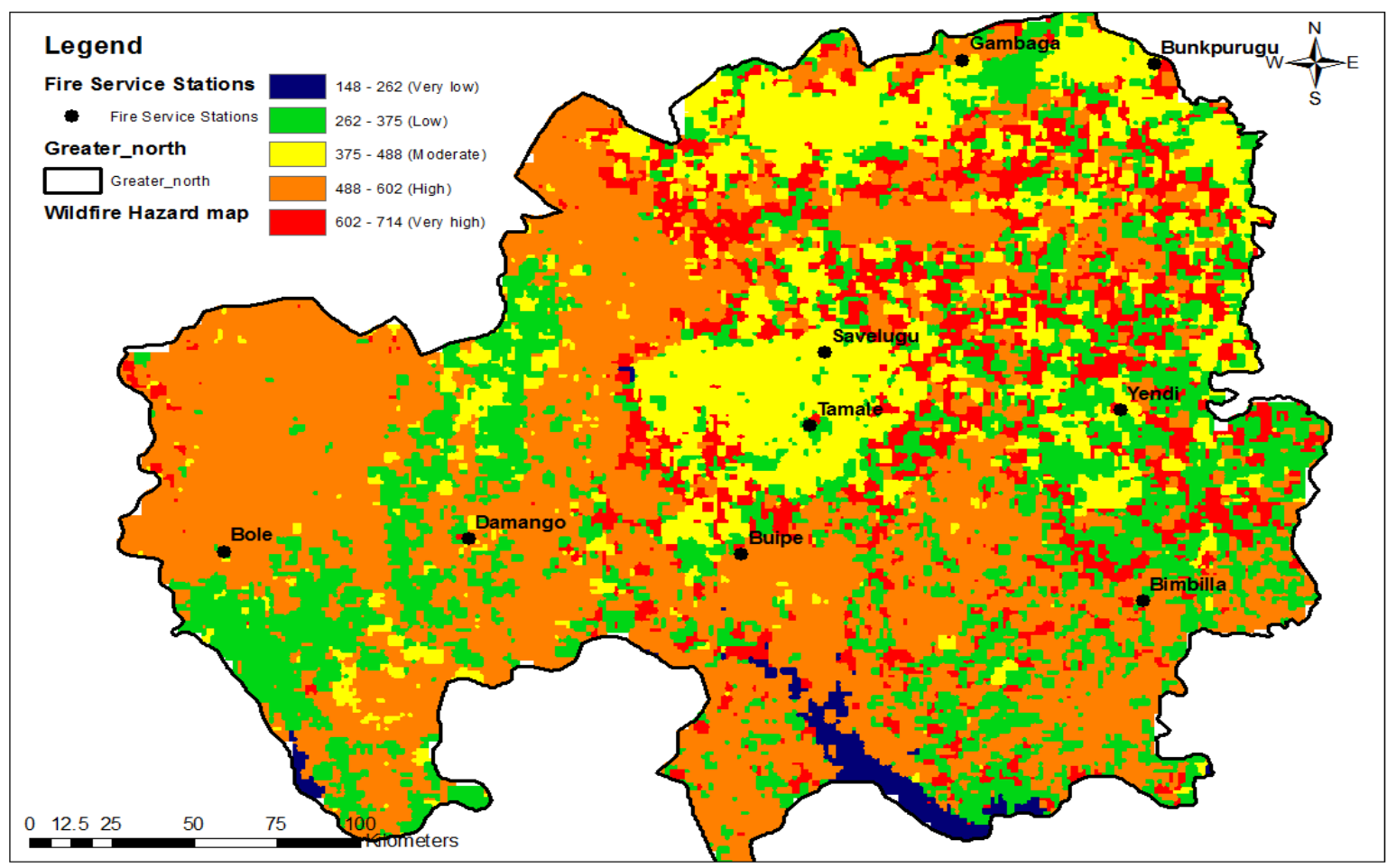

Figure 9: Wildfire hazard model results 


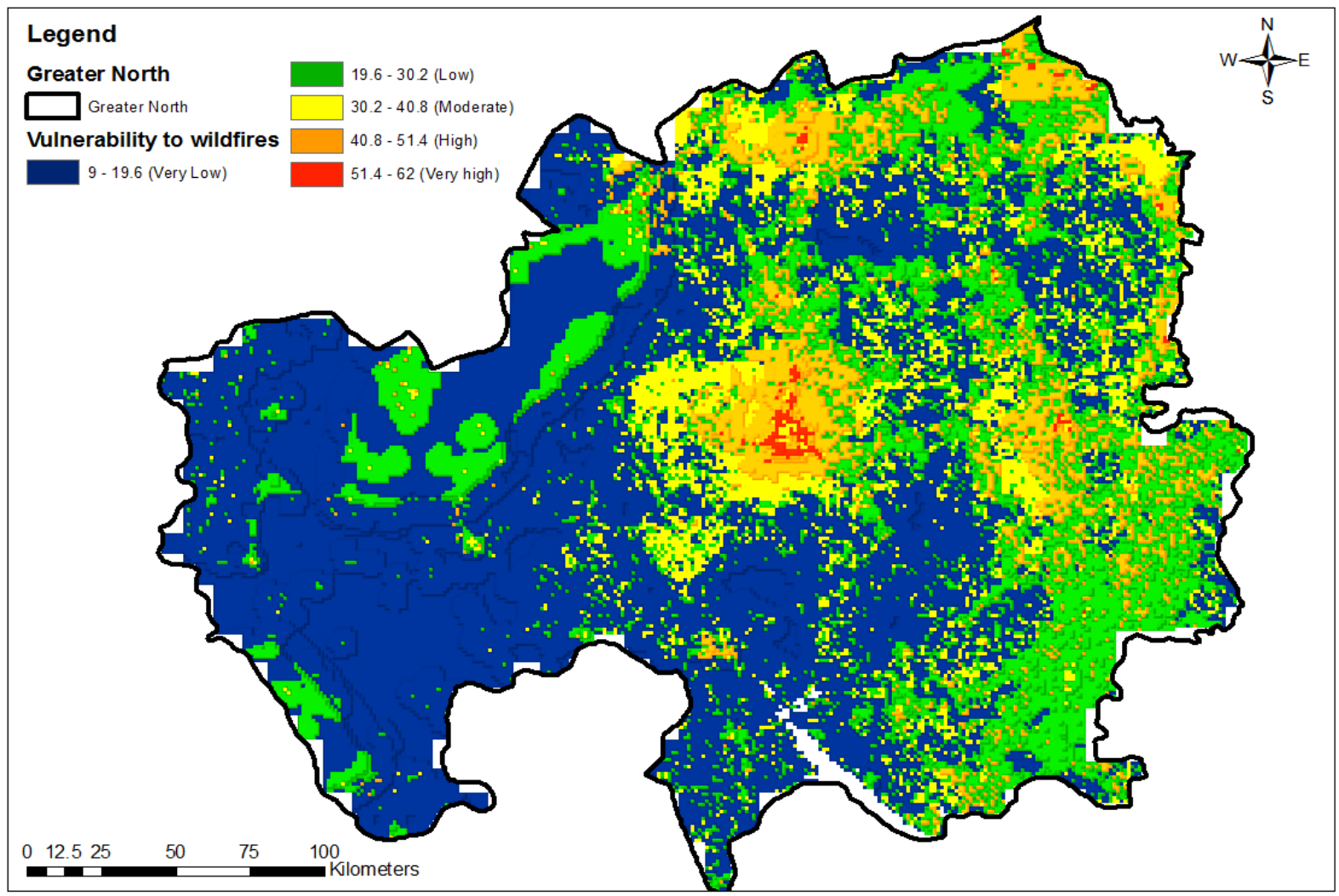

Figure 10: Spatial distribution of vulnerability to wildfires in the Greater North region

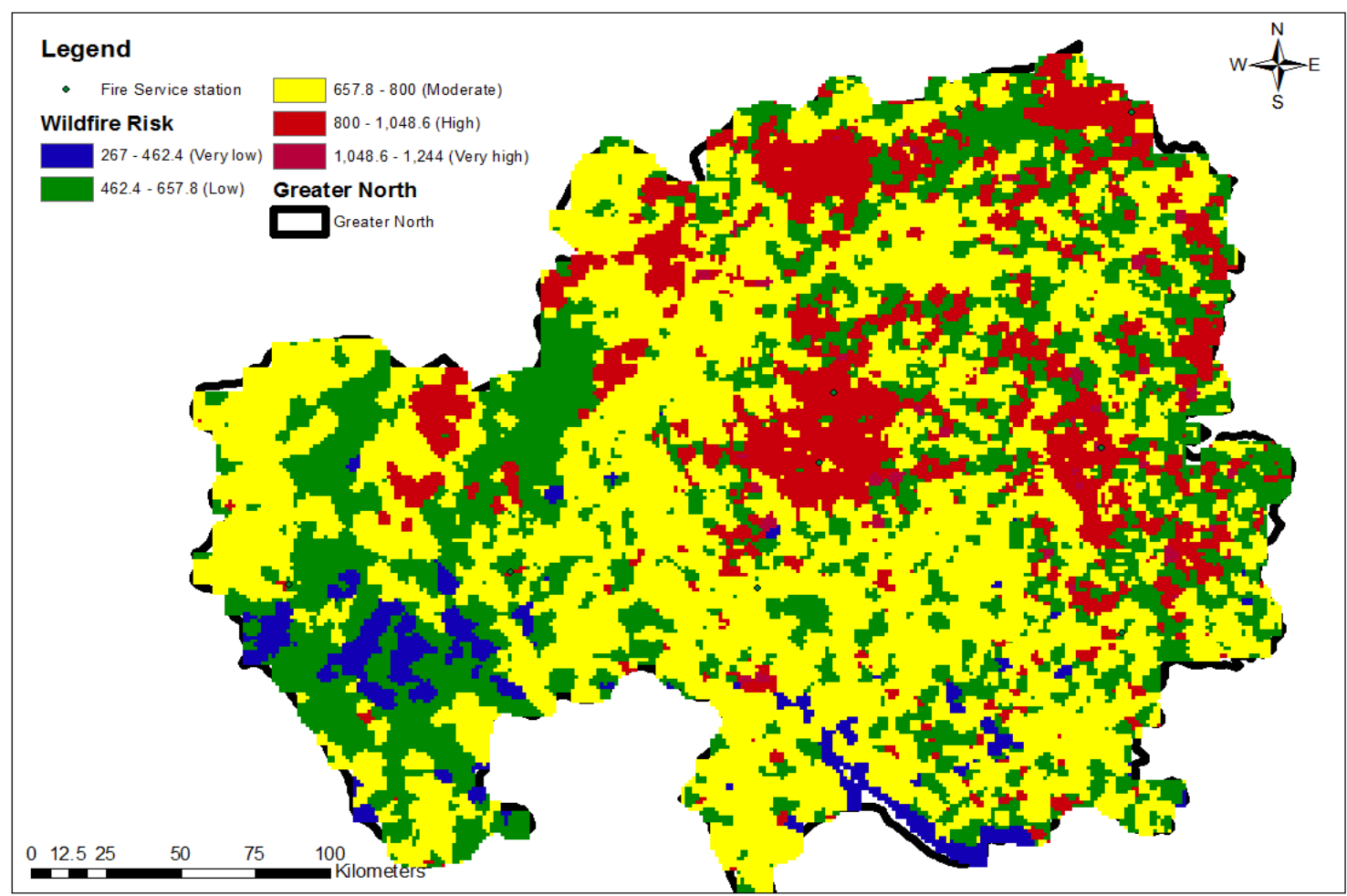

Figure 11: Wildfire risk model results 